\title{
Olfactory Recognition of a Trimethylsilylcarbamate as a Carboxylic Acid
}

D. Jewett

Division of Nuclear Medicine, University of Michigan Medical School, Ann Arbor, MI 48109-0552, USA

Under physiological conditions amines, amino acids, and peptides may react reversibly with carbon dioxide to form carbamates [1]:

$$
\mathrm{R}_{1} \mathrm{R}_{2} \mathrm{NH}+\mathrm{CO}_{2} \rightleftharpoons \mathrm{R}_{1} \mathrm{R}_{2} \mathrm{NC}(\mathrm{O}) \mathrm{O}^{-}+\mathrm{H}^{+}
$$

This reaction has been implicated in the normal function of hemoglobin [2] and possibly of tubulin [3]. A strong case has recently been made that $N$-carboxylation is involved in the excitatory neurotoxicity of cysteine [4] and $\beta-N$ methylamino-L-alanine [5]. The NMDA receptor may recognize the carbamate moiety of $\mathrm{N}$-carboxycysteine as equivalent to the $-\mathrm{CH}_{2} \mathrm{COO}^{-}$ side chain of $N$-methyl-D-aspartate. In addition to degenerative neurotoxicity, such a mechanism may also contribute to reversible $\mathrm{CO}_{2}$ intoxication [6] by causing simultaneous, transient changes in the structure of a number of chemical species in the brain. The implication of reversible $N$-carboxylation as broadly relevant to neuropathology recalls the accidental discovery of another case in which a cellular receptor appears to recognize a carbamate group as a carboxylic acid.

Carbon dioxide inserts into the $\mathrm{Si}-\mathrm{N}$ bond of silylamino groups to form silylcarbamates [7]:

$$
\begin{aligned}
& \mathrm{R}_{1} \mathrm{R}_{2} \mathrm{~N}-\mathrm{Si}\left(\mathrm{R}_{3}\right)_{3}+\underset{\mathrm{CO}_{2}}{\mathrm{CO}} \rightarrow \\
& \mathrm{R}_{2} \mathrm{NC}(\mathrm{O}) \mathrm{O}-\mathrm{Si}\left(\mathrm{R}_{3}\right)_{3}
\end{aligned}
$$

During synthesis with trimethylsilylpiperidine 1 (Fig. 1) [8] the characteristic sour, penetrating odor of a fatty acid was apparent immediately upon contact of the silylamine with $\mathrm{CO}_{2}$. Isolation of the silylcarbamate 2 indicated that it was indeed the source of the odor. The compound was labile in the presence of atmospheric moisture. Filter paper containing the material lost its odor in a few seconds. However, a $1 \%$ dispersion in petrolatum retained the characteristic odor for some time. Apparently the silylcarbamate hydrolyzed in contact with the olfactory epithelium to give the free carbamic acid or anion, an isostere of the powerful odorant, cyclohexane carboxylic acid. The piperidinium salt of the anion 3 lacked the fatty acid odor. The trimethylsilyl group apparently allowed the carbamate to have sufficient volatility and lipophilicity to reach the receptor site.

Because of the lability of the $-\mathrm{C}(\mathrm{O}) \mathrm{O}$ $\mathrm{Si}\left(\mathrm{CH}_{3}\right)_{3}$ group toward atmospheric moisture the more hindered triethylsilyl analog was synthesized. While the fatty acid odor was recognizable and more persistent, the effect was complicated by the camphoraceous odor contributed by the bulky triethylsilyl
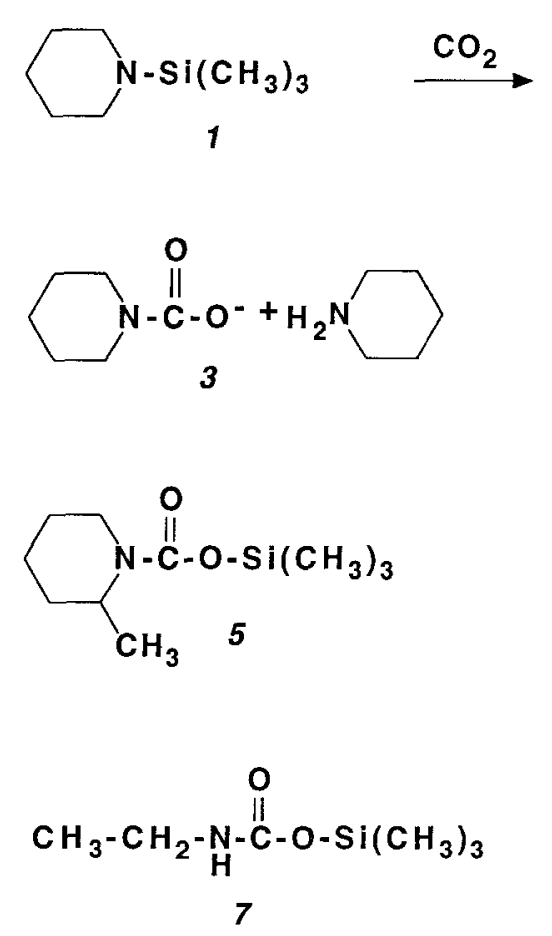<smiles>CCN(C)C(=O)O[SiH](C)C</smiles>

Fig. 1. Carbamate analogs of odoriferous carboxylic acids
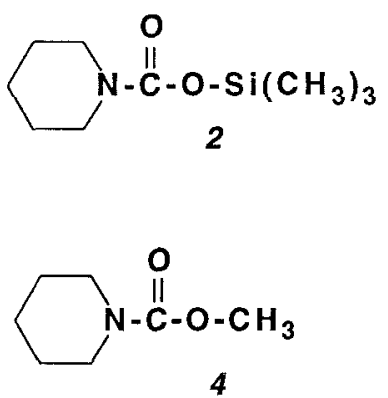

group. The methyl carbamate 4 smelled like an ester. Attempts, though not exhaustive, to modify the amino group $(5-8)$ resulted in compounds which, unlike their carboxylic isosteres, lacked a fatty acid odor. It appears that exact conditions are required for the olfactory effect. This may be related to the fact that cyclohexane carboxylic acid has a low olfactory threshold and is possibly a unique olfactory stimulant in mammals [9].

It was considered that it might be possible to form the $N$-carboxypiperidine moiety in situ on the olfactory membrane. A breathing cone was constructed such that piperidine vapor could be injected into dry air containing varying amounts of $\mathrm{CO}_{2}$. The odor of piperidine was apparent, but there was no odor of fatty acid. The experiment was abandoned because of the powerful cardiac effects of the $\mathrm{CO}_{2}$.

Received June 24, 1992

1. Crooks, J. E., Donnellan, J. P.: J. Chem. Soc. Perkin Trans. 2, 331 (1989)

2. Gros, G., Rollema, H. S.: J. Biol. Chem. 256, $5471(1981)$

2<smiles>CN(C)C(=O)O[SiH3]</smiles> 
3. Clark, R. R., Volpi, M., Berlin, R. D.: Biochemistry 27, 1025 (1988)

4. Nunn, P. B., Davis, A. J., O'Brien, P.: Science 251, 1619 (1991); Olney, J. W., Zorumski, C., Price, M. T., Labruyere, J.: ibid. 248, 596 (1990); 251, 1619 (1991)

5. Nunn, P. B., O'Brien, P.: FEBS Lett. $251,31(1989)$
6. Miller, A. L.: Int. Rev. Neurobiol. 22, 47 (1981); Nutt, D. J.: Pharmacol. Ther. 47, 233 (1990); Meduna, L. J.: Carbon Dioxide Therapy. Oxford: Blackwell 1958

7. Lappert, M. F., Prokai, B.: Adv. Organomet. Chem. 5, 225 (1967)
8. Armitage, D. A., in: The Silicon-Heteroatom Bond, p. 367 (S. Patai, ed.). Chichester: Wiley 1991

9. Bakke, J. M., Figenschou, E.: Comp. Biochem. Physiol. A: Comp. Physiol. 97, 427 (1990)
Naturwissenschaften 79, 518-519(1992) (C) Springer-Verlag 1992

\section{Identification of Anomala schonfeldti Sex Pheromone by High-Resolution GC-Behavior Bioassay}

\author{
W. S. Leal
}

Department of Insect Physiology and Behavior, National Institute of Sericultural and Entomological Science (NISES), Tsukuba, Ibaraki 305, Japan

\section{Hasegawa and M. Sawada \\ Chiba Prefectural Agricultural Experiment Station, 808 Daizenno-cho, Midori-ku, Chiba 266, Japan}

Despite their economic importance as agricultural pests and the high demand for safer agrochemicals, our knowledge of the pheromone chemistry of scarab beetles (Coleoptera: Scarabaeidae) is still very limited. This is mainly due to the lack of uniform and consistent laboratory bioassays, which precludes the identification of these semiochemicals. Recently, this barrier has been overcome by coupling GC-EAD with a simplified laboratory [1] or field bioassay [2]. Nevertheless, attempts to apply GC-EAD to beetles with small antennae, like Anomala schonfeldti (body length $10-12 \mathrm{~mm}$ ), were unrewarding. Therefore, we used high-resolution gas chromatography-behavior bioassay

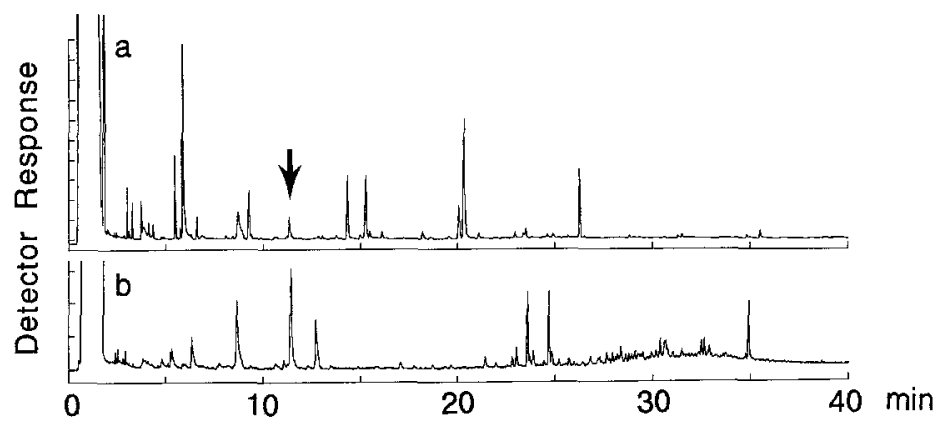

Fig. 1. Gas chromatograms on an HP-1 capillary column obtained from a) the hexane-ether (1:1) active fraction from the airborne volatiles of female $A$. schonfeldti fed on cherry leaves, and b) 0.1 female equivalent of the crude extract generated from eight virgin females without foodstuff. The arrow indicates the active zone at ca. 11.4 min was carried out using the same GC effluent splitter and glass transfer system as for GC-EAD [5]. The exit of the transfer tube capped with a plastic mesh was connected to a rectangular plastic box $(17 \times 12 \times 6 \mathrm{~cm})$ arena covered with wire mesh. The arena was set soon after the solvent peak was eluted and when activity was demonstrated, both the box and the plastic cap were renewed to investigate the occurrence of other active zone(s).

GC-BB on a DB-23 $(30 \mathrm{~m} \times 0.254 \mathrm{~mm}$; $0.25 \mu \mathrm{m}$ ) column operated at $50^{\circ} \mathrm{C}$ for $1 \mathrm{~min}$, programmed at $8^{\circ} \mathrm{C} / \mathrm{min}$ to $210^{\circ} \mathrm{C}$, and held at this temperature for $10 \mathrm{~min}$ [50(1)-210(10)/8] displayed activity at ca. $12.77 \mathrm{~min}$, however, a very broad peak was detected by FID in the region. With a nonpolar column [HP-1], operated at 50(1)-100(1)/3$200(1) / 5-240(10) / 10$, activity appeared only at ca. $11.4 \mathrm{~min}$, where a small peak was detected (Fig. 1 a). A crude extract from the airborne volatiles from females without foodstuff demonstrated activity and gave the major peak in the same region (Fig. 1b). Males responded by walking or flying towards the GC-effluent transfer tube (Fig. 2a), gathering on the plastic mesh (Fig. 2 b, c) and trying to copulate with each other. Activity was enhanced by the use of the plastic mesh probably due to the partial condensation of the active material on the net, therefore, increasing the elution time into the arena. Consequently, full activation of the insects was achieved. Interestingly, a net removed soon after the active material eluted, elicited sexual behavior in a different group of insects even $3 \mathrm{~min}$ later. Pheromonal activity was also demonstrated at ca. $23.3 \mathrm{~min}$ with a DBwax column $(30 \mathrm{~m} \times 0.25 \mathrm{~mm} ; 0.25$ $\mu \mathrm{m})$ operated at $50(1)-180(1) /$ 4-210(10)/10 where single peaks appeared either from the hexane-ether (1:1) fraction or from the crude airborne volatiles from virgin females. No 